\title{
Seed Germination Biology of Four Pomegranate (Punica granatum) Cultivars from Xinjiang, China
}

\author{
Dilinuer Shalimu and Ke Li \\ National Engineering Laboratory for Tree Breeding, College of Biological \\ Sciences and Biotechnology, Beijing Forestry University, Beijing 100083, \\ China
}

\section{Carol C. Baskin}

Department of Biology, University of Kentucky, Lexington, KY 40506; and Department of Plant and Soil Sciences, University of Kentucky, Lexington, KY 40546

\section{Jerry M. Baskin \\ Department of Biology, University of Kentucky, Lexington, KY 40506}

\section{Yujun Liu ${ }^{1}$}

National Engineering Laboratory for Tree Breeding, College of Biological Sciences and Biotechnology, Beijing Forestry University, Beijing 100083, China

Additional index words. embryo growth potential, cold stratification, physiological dormancy, surfuric-acid scarification, warm stratification

\begin{abstract}
Pomegranate is an important fruit crop cultivated in many countries, and development of new cultivars depends on the plant breeders being able to produce plants from seeds. Poor quality and low yield of cultivars are widespread problems that greatly restrict development of the pomegranate industry. Our purpose was to gain a better understanding of the seed dormancy-breaking and germination requirements of four cultivars of pomegranate from Xinjiang Province, China, which would be useful in improving old cultivars and developing new ones. Fresh pomegranate seeds incubated on moist filter paper imbibed water, but they germinated to only $16 \%$ to $20 \%$. Sulfuric acid scarification, cold stratification, and warm followed by cold stratification significantly increased germination percentages. Seeds soaked in concentrated $\mathrm{H}_{2} \mathrm{SO}_{4}$ for 40 minutes followed by cold stratification for 2 months germinated to $65 \%$, and those warm stratified for 1-3 months followed by cold stratification for 2 months germinated to $75 \%$ to $80 \%$. Seeds of pomegranate have nondeep physiological dormancy (PD).
\end{abstract}

Pomegranate [Punica granatum L. (Lythraceae)] is believed to have originated in the southern Caspian region and northeastern Turkey, and the Mediterranean Basin is an important diversification center of the species (Halilova and Yildiz, 2009; Levin, 1994). Today, it is extensively cultivated in Afghanistan, Egypt, Italy, India, China, United States, Chile, Spain, and Turkey (Stover and Mercure, 2007), and in Turkey in the Mediterranean, Aegean, and southeastern Anatolia regions (Ercisli, 2004; Ozgen et al., 2008). Pomegranate was introduced to China 2000 years ago, and famous production areas include Lintong in Shanxi Province, Zaozhuang

\footnotetext{
Received for publication 20 Jan. 2015. Accepted for publication 3 Apr. 2015.

This work was supported by the Fundamental Research Funds for the Central Universities (no. BLYJ201413) and in part by the Program of Science and Technology Innovation of Beijing Forestry University (200-1244901).

${ }^{1}$ To whom reprint requests should be addressed; e-mail yjliubio@bjfu.edu.cn.
}

in Shandong Province, Huaiyuan in Anhui Province, Huili in Sichuan Province, Mengzi in Yunnan Province, and Kashgar in Xinjiang Province (Wang et al., 2010).

Although some crop species can be propagated vegetatively, development of new cultivars depends on the plant breeder being able to produce plants from seeds. Pomegranate is a shrub or a small tree widely planted in both tropical and subtropical areas (Wang et al., 2013). Its roots, bark, fruit juice, and dried fruit peel contain abundant anthocyanins and/or hydrolysable tannins that have strong antioxidant (Chidambara et al., 2002), antitumor (Afaq et al., 2005; Hora et al., 2003), and hypolipidemia (Huang et al., 2005) activities. In China, pomegranate is an important crop in six provinces, with about 238 cultivars (Feng and Chen, 2000). However, there are widespread problems with pomegranate cultivars, including poor quality and low yield, which greatly limit the development of the pomegranate industry (Gulimire et al., 2003). Thus, improvement of old cultivars and development of new ones are of great significance (Mars, 2000).
The purpose of our study was to gain a better understanding of the dormancy breaking and germination requirements of pomegranate seeds to facilitate growing genetically diverse plants for selection of new cultivars. Previous studies have shown that cold stratification, soaking, or both in concentrated $\mathrm{H}_{2} \mathrm{SO}_{4}$ can increase the germination percentage of seeds of this species (Gokturk et al., 2012; Olmez et al., 2007; Piotto et al., 2003; Rawat et al., 2010; Riley, 1981; Yucedag and Gultekin, 2009). However, no studies have been conducted on seed dormancy and germination of cultivars that grow in the cold desert region of Xinjiang Province in northwest China. Cultivation of pomegranate is concentrated in southern Xinjiang, particularly in Kashgar, Hotan, and Turpan (Gulimire et al., 2003). Four cultivars were chosen from these three production areas, based on volume of sales and popularity among the people, as our study material. We tested the effects of afterripening in dry storage at room temperature and at $4{ }^{\circ} \mathrm{C}$, sulfuric acid scarification, treatment with gibberellic acid $\left(\mathrm{GA}_{3}\right)$, cold (moist) stratification, acid scarification plus cold stratification, and warm stratification followed by cold stratification on breaking seed dormancy in the four Xinjiang cultivars Kashgar Akeqishiliu (I), Yecheng Suanshiliu (II), Hotan CeLe1\#shiliu (III), and Turpan Suanshiliu (IV) from Kashgar, Kashgar, Hotan, and Turpan, respectively.

\section{Materials and Methods}

Seed collection and handling. Freshly matured fruits of cultivars Kashgar Akeqishiliu (I) Yecheng Suanshiliu (II) Hotan CeLe1\#shiliu (III), and Turpan Suanshiliu (IV) were collected in Xinjiang Province in Nov. 2012 and 2013. The annual average temperature in the Trafigura and Turpan basins in Xinjiang is 14.1 and $15.0^{\circ} \mathrm{C}$, respectively, and these are the average highest annual temperatures in Xinjiang ( $\mathrm{Yu}$ and Liu, 2007). The highest average monthly temperatures in Kashgar, Hotan, and Turpan are $25.5,26.5$, and $32.5^{\circ} \mathrm{C}$ (July), respectively, and the average lowest temperatures are -5.5 , -4 , and $-7.5^{\circ} \mathrm{C}$ (January), respectively.

Fruits were stored dry at room conditions in Xinjiang for $4 \mathrm{~d}$, and then transported to Beijing, where seeds were separated from the fruits, washed, and stored in cloth bags under ambient laboratory (room) conditions until used in experiments. Tetrazolium chloride tests showed that nearly all fresh seeds and about $95 \%$ of the nongerminated seeds in the various germination studies were viable. A preliminary germination test showed that 25 / $15^{\circ} \mathrm{C}$ is the optimum temperature regime for germination, and thus this temperature regime was used in all germination tests.

Morphological characteristics of seeds. One-hundred mature, well-developed seeds of each of the four pomegranate cultivars were selected haphazardly, and their color and shape observed. Length and width of each seed also were measured using digital calipers. Ten replications of 100 seeds of each of the four cultivars were weighed $(0.0001 \mathrm{~g})$ using an electronic balance. 
Water absorption. Water absorption (imbibition) was monitored for four replications of 100 fresh seeds of each cultivar. Seeds of the four pomegranate cultivars were placed on filter paper moistened with distilled water in 9-cmdiameter petri dishes and kept at laboratory conditions. At time 0 and after 5, 10, 20, and 30 min and $1,3,5,8,12,20,33,45,57,69$, and $81 \mathrm{~h}$, each replication of 100 seeds was blotted dry, weighed to the nearest $0.1 \mathrm{mg}$, and returned to the petri dish. The amount of water taken up by each replication after each imbibition period was calculated using the following equation:

$$
\% \mathrm{Wi}=\frac{(\mathrm{Wi}-\mathrm{Wf})}{\mathrm{Wf}} 100
$$

where Wi and Wf are the mass of imbibed and nonimbibed seeds, respectively.

Effect of dry storage at ambient room temperature on dormancy break and moisture content. Seeds of the four pomegranate cultivars were stored for 0 month (control), 1, 3, 6, 8 , and 12 months in a closed cotton bag under laboratory room conditions. After each period of storage, four replications of 25 seeds each were incubated in petri dishes on two sheets of filter paper moistened with distilled water at $25 / 15^{\circ} \mathrm{C}$ in light $($ light $=12 \mathrm{~h}$ each day, $\approx 100$ $\mu \mathrm{mol} \cdot \mathrm{m}^{-2} \cdot \mathrm{s}^{-1}, 400$ to $700 \mathrm{~nm}$, cool-white fluorescent light, hereafter light) and in constant darkness for $28 \mathrm{~d}$. Seeds incubated in light were checked daily for germination, but those incubated in darkness were checked only after $28 \mathrm{~d}$ to avoid exposing them to any light during incubation.

Moisture content was determined at time 0 (fresh-weight basis) and at monthly intervals for 1 year for seeds of all four cultivars stored in the laboratory. Five groups of 100 seeds were weighed to the nearest $0.1 \mathrm{mg}$ and then placed in a drying oven at $80^{\circ} \mathrm{C}$ for $72 \mathrm{~h}$. Percentage of seed moisture content (MC) was calculated as follows:

$$
\% \mathrm{MC}=\frac{(\text { fresh mass }- \text { dry mass })}{\text { fresh mass }} 100
$$

Effect of dry storage at low temperature on dormancy break. One week after collection, seeds of each of the four cultivars were placed in a paper bag at $4{ }^{\circ} \mathrm{C}$. After 0,1 , and 2 months of storage, four replications of 25 seeds of each cultivar were incubated at $25 / 15^{\circ} \mathrm{C}$ in light and checked for germination daily for $28 \mathrm{~d}$.

Effect of cold stratification on dormancy break. Fresh seeds of the four pomegranate cultivars were cold-stratified on moist filter paper in 15-cm-diameter petri dishes that were placed in a light-proof black bag at $4{ }^{\circ} \mathrm{C}$ for 0 (control), 1, 2, and 3 months. After cold stratification, four replications of 25 seeds each of each cultivar were incubated at $25 / 15^{\circ} \mathrm{C}$ in light for $28 \mathrm{~d}$ as described above.

Effect of concentrated sulfuric acid on dormancy break. Fresh seeds of the four pomegranate cultivars were soaked in concentrated $\mathrm{H}_{2} \mathrm{SO}_{4}(98 \%)$ for 0 (distilled water control), 10, 20,30,40, and $50 \mathrm{~min}$, rinsed in distilled water, and then incubated at $25 / 15^{\circ} \mathrm{C}$ in light for $28 \mathrm{~d}$ as described above.

Effect of $\mathrm{GA}_{3}$ on dormancy break. Four replications of 25 seeds of each of the four pomegranate cultivars were incubated in 0 (distilled water control), $0.1,1.0$, and $10.0 \mathrm{~mol} \cdot \mathrm{m}^{-3}$ $\mathrm{GA}_{3}$ solutions at $25 / 15^{\circ} \mathrm{C}$ in light for $28 \mathrm{~d}$ as described above.

Effect of concentrated sulfuric acid followed by cold stratification on dormancy break. Fresh seeds of the four pomegranate cultivars were soaked in concentrated $\mathrm{H}_{2} \mathrm{SO}_{4}$ for 0 (control), 10, 20,30, 40, and $50 \mathrm{~min}$, rinsed in distilled water, and then coldstratified on moist filter paper in $15-\mathrm{cm}$ diameter petri dishes that were placed in darkness at $4{ }^{\circ} \mathrm{C}$ for 0,4 , and 8 weeks. Then, four replications of 25 seeds each of each cultivar were incubated at $25 / 15^{\circ} \mathrm{C}$ in light for $28 \mathrm{~d}$ as described above.

Effect of warm stratification followed by cold stratification on dormancy break. Seeds of the four pomegranate cultivars were warm stratified on moist filter paper in $15-\mathrm{cm}$ diameter petri dishes in light at $25 / 15^{\circ} \mathrm{C}$ for 1,2 or 3 months. Then, the seeds were coldstratified in darkness at $4{ }^{\circ} \mathrm{C}$ for 2 months. After cold stratification, four replications of 25 seeds of each cultivar were incubated at $25 / 15^{\circ} \mathrm{C}$ in light for $28 \mathrm{~d}$ as described above.

Data analysis. Data were analyzed using SPSS for Windows, Version 16.0 (SPSS Inc., Chicago, IL). All data were analyzed for normality and homogeneity of variance before analysis. One-way analysis of variance (ANOVA) was used to test for differences among cultivars I, II, III, and IV in length, width, and mass of seeds. Variances of data for cultivars I, II, III, and IV were not homogeneous, thus they were $\log _{10}$ transformed before analysis to ensure homogeneity of variance. In cases where the ANOVA assumptions continued to be violated following data transformation, treatment differences were assessed by using the more conservative Kruskal-Wallis nonparametric test. Three-way ANOVA was used to test for significance of main effects (light condition, storage time, and cultivar and their interaction) on germination in the "Effect of dry storage at ambient room temperature on dormancy break" experiment. Tukey's honest significant difference test was used to test for differences $(P<0.05)$ among individual treatments. Statistical tests were conducted at
$P=0.05$. Values are means $\pm 1 \mathrm{SE}$ (Sokal and Rohlf, 1995).

\section{Results}

Morphological characteristics of seeds. The color and shape of dry seeds of the four pomegranate cultivars are similar, i.e., white and irregular shape. Length, width, and mass of seeds did not differ significantly among 'Kashgar Akeqishiliu' (I), 'Yecheng Suanshiliu' (II), and 'Hotan CeLe1\#shiliu' (III) $(P=0.687)$, but those of 'Turpan Suanshiliu' (IV) differed significantly in all three measures from the other three cultivars $(P<0.01)$ (Table 1$)$.

Water absorption. The curves for water uptake of seeds of the four pomegranate cultivars were similar (data not shown). Thus, for example, for seeds of the Kashgar Akeqishiliu (I) cultivar increase in mass after $5 \mathrm{~min}$ and $20 \mathrm{~h}$ was $17.1 \% \pm 1.4 \%$ and $50.1 \%$ $\pm 1.2 \%$, respectively. Seeds were fully imbibed after $33 \mathrm{~h}$, and the final increase in mass was $53.92 \% \pm 0.08 \%$.

Effect of dry storage (after-ripening) at ambient room temperature on dormancy break and moisture content. Three-way ANOVA showed that germination was significantly affected by light condition $(P<$ $0.01)$ and storage time $(P=0.028)$ (Table 2$)$. There were no significant interactions in germination percentage by cultivars $(P=$ $0.296)$, between cultivars and storage time $(P=0.281)$, cultivars and light $(P=0.517)$, storage time and light $(P=0.072)$, or among the interaction of the three factors $(P=0.293)$ (Table 2). Germination of fresh seeds of cultivars I, II, III, and IV in light was $19 \%$, $20 \%, 18 \%$, and $16 \%$, respectively, but in constant darkness it was only $6 \%, 5 \%, 6 \%$, and 4\%, respectively (Fig. 1). After 3 months of incubation, seeds of cultivars I, II, III, and IV had germinated to $12 \%, 10 \%, 13 \%$, and $11 \%$, respectively, in light, but to only $4 \%$, $4 \%, 2 \%$, and $3 \%$, respectively, in dark. Germination of cultivars I, II, III, and IV in light was $9 \%, 7 \%, 6 \%$, and $9 \%$, respectively, after 6 months of storage and $2 \%, 1 \%, 1 \%$, and $0 \%$ respectively, after 9 months of storage. However, germination of all four cultivars had declined to $0 \%$ in light after 12

Table 1. Comparison of the morphology and mass (mean $\pm \mathrm{SE}$ ) of seeds of the four pomegranate cultivars: Kashgar Akeqishiliu (I), Yecheng Suanshiliu (II), Hotan CeLe1\#shiliu (III), and Turpan Suanshiliu (IV). Different letters within a row indicate significant differences (Tukey's honest significant difference, $P=0.05$ ).

\begin{tabular}{lcccc}
\hline Cultivar & I & II & III & IV \\
\hline Seed length $(\mathrm{mm})(n=100)$ & $6.750 \pm 0.048 \mathrm{a}$ & $6.799 \pm 0.048 \mathrm{a}$ & $6.806 \pm 0.047 \mathrm{a}$ & $6.485 \pm 0.044 \mathrm{~b}$ \\
Seed width $(\mathrm{mm})(n=100)$ & $3.347 \pm 0.033 \mathrm{a}$ & $3.344 \pm 0.029 \mathrm{a}$ & $3.416 \pm 0.032 \mathrm{a}$ & $3.523 \pm 0.036 \mathrm{~b}$ \\
Mass of 100 seeds $(\mathrm{g})(n=10)$ & $2.588 \pm 0.008 \mathrm{a}$ & $2.508 \pm 0.017 \mathrm{a}$ & $2.557 \pm 0.010 \mathrm{a}$ & $2.766 \pm 0.010 \mathrm{~b}$ \\
\hline
\end{tabular}

Table 2. Three-way analysis of variance of effects of cultivar, light condition, storage time, and their interactions on germination of pomegranate seeds stored dry under laboratory conditions.

\begin{tabular}{lcccrc}
\hline Source & $\mathrm{df}$ & Sum of squares & Mean of squares & $F$ value & $P$ value \\
\hline Light $(\mathrm{L})$ & 1 & $1,441.500$ & $1,441.500$ & 312.614 & $<0.01$ \\
Retrieval time (R) & 2 & 34.646 & 17.323 & 3.757 & 0.028 \\
Cultivar (C) & 3 & 17.375 & 5.792 & 1.256 & 0.296 \\
$\mathrm{~L} \times \mathrm{R}$ & 2 & 25.17 & 12.594 & 2.731 & 0.072 \\
$\mathrm{~L} \times \mathrm{C}$ & 3 & 10.583 & 3.528 & 1.765 & 0.517 \\
$\mathrm{R} \times \mathrm{C}$ & 6 & 35.188 & 5.865 & 1.272 & 0.281 \\
$\mathrm{~L} \times \mathrm{R} \times \mathrm{C}$ & 6 & 34.479 & 5.747 & 1.246 & 0.293 \\
\hline
\end{tabular}


months of storage and to $0 \%$ in darkness after 6 months of storage (Fig. 1).

During 12 months of dry storage, seed moisture content decreased from $7.95 \% \pm$ $0.14 \%$ (fresh seeds) to $5.33 \% \pm 0.28 \%$.

Effect of dry storage at low temperature on dormancy break. Dry storage at low temperature had a significant effect on germination percentages $(P<0.01)$; however, there were no significant differences among cultivars $(P=0.808)$. Germination in light at $25 / 15^{\circ} \mathrm{C}$ of fresh seeds of cultivars I, II, III, and IV was $21 \%, 19 \%, 23 \%$, and $21 \%$, respectively, and after 2 months dry storage at $4{ }^{\circ} \mathrm{C}$ it was $31 \%$, $34 \%, 36 \%$, and $33 \%$, respectively.

Effect of cold stratification on dormancy break. Cold stratification had a significant effect on breaking seed dormancy. After 1 month of cold stratification, germination of cultivars I, II, III, and IV was $19 \%, 20 \%$,

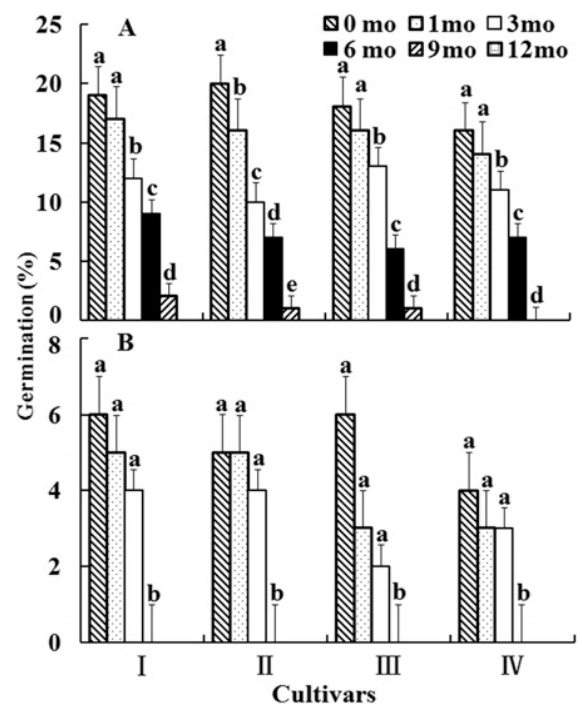

Fig. 1. Final germination percentages (mean $\pm \mathrm{SE}$ ) of seeds of the four pomegranate cultivars incubated at $25 / 15^{\circ} \mathrm{C}$ in light (A) and in dark (B) following $0,1,3,6,9$, and 12 months of dry storage at laboratory conditions. For each cultivar, different letters for a cultivar in light or in darkness indicate significant differences. No seeds germinated in light after 12 months of storage, and no seeds germinated in darkness after 6,9 , or 12 months of storage. Cultivars: Kashgar Akeqishiliu (I), Yecheng Suanshiliu (II), Hotan CeLe1\#shiliu (III), and Turpan Suanshiliu (IV).

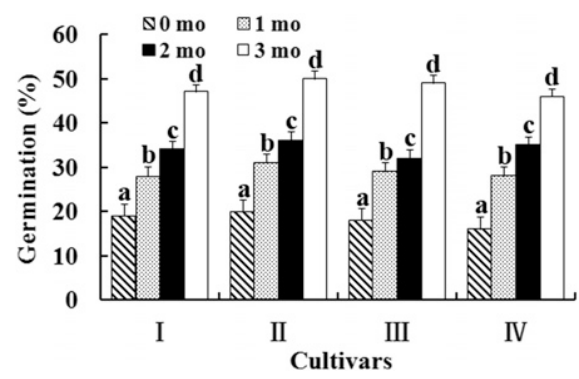

Fig. 2. Final germination percentages $(m e a n \pm S E)$ of seeds of the four pomegranate cultivars incubated at $25 / 15{ }^{\circ} \mathrm{C}$ in light after cold stratification for $0,1,2$, and 3 months. For each cultivar, different letters indicate significant differences among the four treatments.
$18 \%$, and $16 \%$, respectively, in light at $25 / 15^{\circ} \mathrm{C}$, and after 3 months it had increased to $47 \%$, $50 \%, 49 \%$, and $46 \%$, respectively (Fig. 2). Length of cold stratification period $(P<0.01)$ had a significant effect on germination, but cultivar did not $(P=0.688)$.

Effect of concentrated sulfuric acid on dormancy break. Germination percentage of seeds of the four cultivars increased with 0 - to 40-min soaking time in concentrated $\mathrm{H}_{2} \mathrm{SO}_{4}$, but for seeds soaked for $50 \mathrm{~min}$ it decreased to the same level as the control (Fig. 3). Soaking time had a significant effect on germination $(P<0.01)$, but cultivar did not $(P=0.636)$.

Effect of $\mathrm{GA}_{3}$ on dormancy break. Germination percentage of all four cultivars was significantly increased by $1.0 \mathrm{~mol} \cdot \mathrm{m}^{-3} \mathrm{GA}_{3}$ but not by 0.1 and $10 \mathrm{~mol} \cdot \mathrm{m}^{-3} \mathrm{GA}_{3}(P>0.05)$ (Fig. 4).

Effect of concentrated sulfuric acid followed by cold stratification on dormancy break. Soaking for $40 \mathrm{~min}$ in concentrated $\mathrm{H}_{2} \mathrm{SO}_{4}$ followed by cold stratification for 2 months was optimal for germination of fresh seeds. Germination of seeds of cultivars I, II, III, and IV was $64 \%, 63 \%, 65 \%$, and $62 \%$, respectively, in light at $25 / 15{ }^{\circ} \mathrm{C}$. Soaking time and cold stratification time $(P<0.01)$ had significant effects on germination, but cultivar did not $(P=0.736)$ (Fig. 5).

Effect of warm stratification followed by cold stratification on dormancy break. Warm stratification followed by cold stratification had a positive effect on breaking seed dormancy. Increasing the length of the warm stratification period from 1 to 2 or 3 months significantly increased germination percentages $(P<0.01$, data not shown), but the difference among germination percentages for 2 and 3 months warm-stratified seeds was not significant $(P=0.937)$. Data for the best combination of warm plus cold stratification for promoting germination are shown in Fig. 6. There was no effect of cultivar on germination $(P=0.822)$.

\section{Discussion}

The Nikolaeva-Baskin seed dormancy classification systems include five classes of dormancy: PD, morphological dormancy (MD), morphophysiological dormancy (MPD), physical dormancy (PY), and combinational dormancy (PY + PD) (Baskin and Baskin, 2004, 2014). One-hundred percent of the pomegranate seeds incubated on moist filter paper imbibed, demonstrating that they have a water-permeable seedcoat and therefore do not have PY or PY+PD. Further, the embryo is fully developed (Martin, 1946). In which case, the seeds do not have MD or MPD. Thus, the seeds have PD. Further, since acid scarification and $\mathrm{GA}_{3}$ promoted germination, we conclude that seeds of pomegranate have the nondeep level of PD (Baskin and Baskin, 2004, 2014).

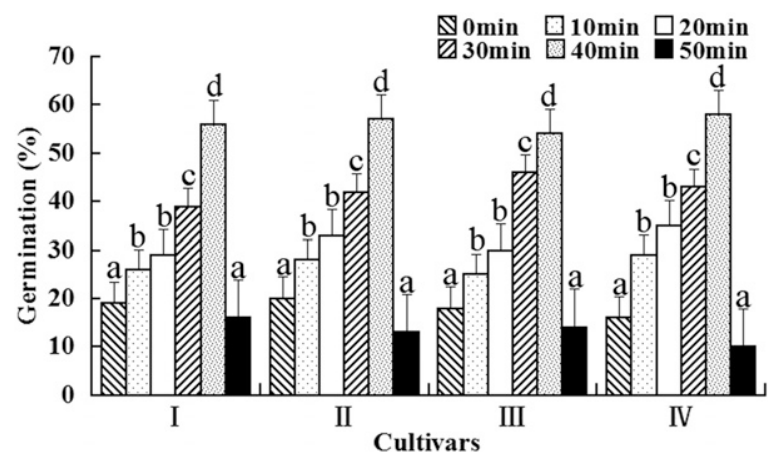

Fig. 3. Final germination percentages (mean $\pm \mathrm{SE}$ ) of seeds of the four pomegranate cultivars incubated at $25 / 15^{\circ} \mathrm{C}$ in light after soaking for 0 (control), 10, 20, 30, 40, and $50 \mathrm{~min}$ in concentrated $\mathrm{H}_{2} \mathrm{SO}_{4}$. For each cultivar, different letters indicate significant differences across all treatments.

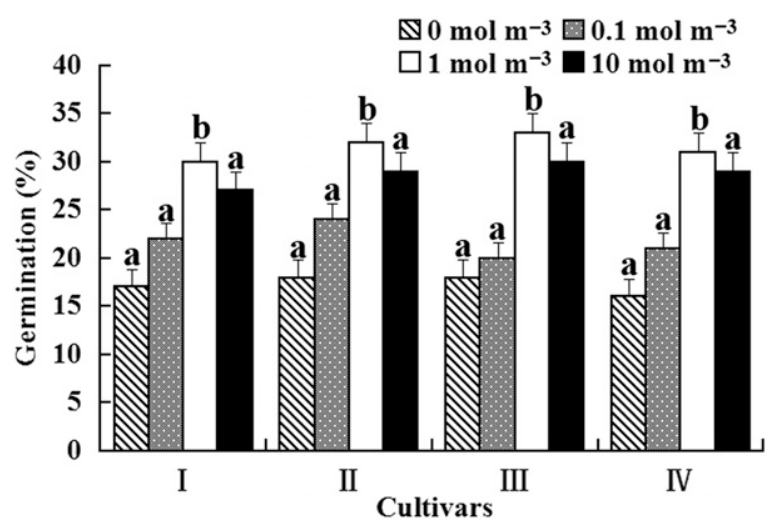

Fig. 4. Effect of gibberellic acid on germination percentage (mean \pm SE) of seeds of four pomegranate cultivars incubated at $25 / 15^{\circ} \mathrm{C}$ in light. For each cultivar, different letters indicate significant differences across all treatments. 


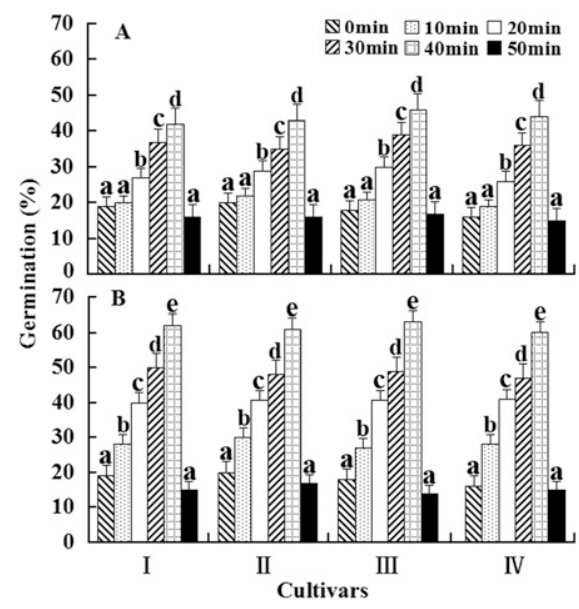

Fig. 5. Final germination percentages (mean $\pm \mathrm{SE}$ ) of seeds of the four pomegranate cultivars incubated at $25 / 15{ }^{\circ} \mathrm{C}$ in light after soaking for 0 (control), 10, 20,30, 40, and $50 \mathrm{~min}$ in concentrated $\mathrm{H}_{2} \mathrm{SO}_{4}$ followed by cold stratification for 1 month (A) and 2 months (B). For each cultivar, different letters indicate significant differences across all treatments.

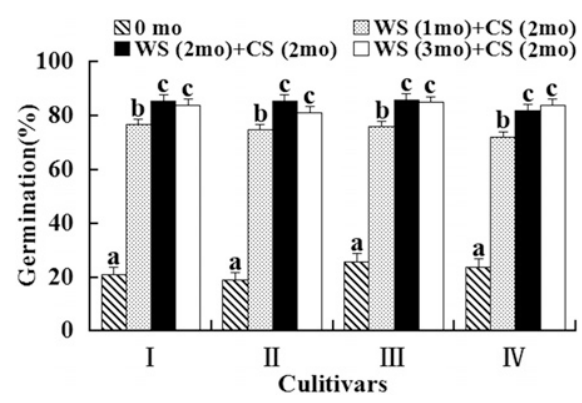

Fig. 6. Final germination percentages (mean $\pm \mathrm{SE}$ ) in light at $25 / 15{ }^{\circ} \mathrm{C}$ of seeds of the four pomegranate cultivars warm stratified (WS) for 1,2 , and 3 months followed by cold stratification (CS) for 2 months. For each cultivar, different letters indicate significant differences across all treatments.

Rawat et al. (2010) found that wild pomegranate seeds germinated to $92 \%$ after $30 \mathrm{~d}$ of cold stratification at $5{ }^{\circ} \mathrm{C}$. Acid scarification followed by cold stratification also has been found to break dormancy. Olmez et al. (2007) obtained the highest germination $(84.8 \%)$ in seeds that were soaked in $\mathrm{H}_{2} \mathrm{SO}_{4}$ for $15 \mathrm{~min}$ and then cold stratified for $60 \mathrm{~d}$, and Gokturk et al. (2012) obtained $60.7 \%$ germination after $30 \mathrm{~min}$ of soaking in $\mathrm{H}_{2} \mathrm{SO}_{4}$ followed by cold stratification for $45 \mathrm{~d}$. In the present study, seeds soaked in $\mathrm{H}_{2} \mathrm{SO}_{4}$ for 40 min followed by cold stratification for 2 months germinated to $65 \%$. Obviously, soaking in $\mathrm{H}_{2} \mathrm{SO}_{4}$ lowers the mechanical resistance to the seedcoat so that the embryo with low growth potential can germinate.
Riley (1981) reported that seeds of pomegranate cold stratified at 1 to $5{ }^{\circ} \mathrm{C}$ for 30 to $60 \mathrm{~d}$ germinated to $91 \%$ to $96 \%$. In our study, seeds of pomegranate cold stratified at $4{ }^{\circ} \mathrm{C}$ for 2 months germinated to $48 \%$ to $50 \%$ (Fig. 2). However, seeds warm stratified for 1 to 3 months followed by cold stratification for 2 months germinated to $75 \%$ to $80 \%$. Thus, warm plus cold stratification was superior to cold stratification alone in breaking seed dormancy in the four cultivars investigated in our study.

Scarification of pomegranate seeds with concentrated sulfuric acid significantly increased germination percentages in all four cultivars. However, the investigator needs to be aware of the possible danger that can result from use of this strong acid. In view of the possible danger of using concentrated sulfuric acid and the fact that seeds of pomegranate germinated to higher percentages with warm plus cold stratification than with either acid scarification, cold stratification, or scarification with concentrated $\mathrm{H}_{2} \mathrm{SO}_{4}$ followed by cold stratification, we recommend warm moist followed by cold moist stratification treatments for breaking dormancy in seeds of the four cultivars investigated in this study.

\section{Literature Cited}

Afaq, F., M. Saleem, C.G. Krueger, J.D. Reed, and H. Mukhtar. 2005. Anthocyanin and hydrolyzable tannin-rich pomegranate fruit extract modulates MAPK and NFkappaB pathways and inhibits skin tumorigenesis in CD-1 mice. Intl. J. Cancer 113:423-433.

Baskin, C.C. and J.M. Baskin. 2014. Seeds: Ecology, biogeography and evolution of dormancy and germination. 2nd ed. Elsevier/Academic Press, San Diego, CA.

Baskin, J.M. and C.C. Baskin. 2004. A classification system for seed dormancy. Seed Sci. Res. 14:1-16.

Chidambara Murthy, K.N., G.K. Jayaprakasha, and R.P. Singh. 2002. Studies on antioxidant activity of pomegranate (Punica granatum) peel extract using in vivo models. J. Agr. Food Chem. 50:4791-4795.

Ercisli, S. 2004. A short review of the fruit germplasm resources of Turkey. Genet. Resour. Crop. Eviron. 51:419-435.

Feng, Y.Z. and D.J. Chen. 2000. Superior varieties and their high-effective culture technique of pomegranate. Henan Science and Technology Press (in Chinese), Zhengzhou, Henan, China.

Gokturk, A., Z. Olmez, B. Karasah, and H. Surat. 2012. Effects of cold stratification and sulphuric acid pre-treatments on germination of pomegranate (Punica granatum L.) seeds in greenhouse and laboratory conditions. Sci. Res. Essays 7:2225-2229.

Gulimire, H.L. Dong, and Julaiti. 2003. The industry status and future development of pomegranate in Xinjiang. Northw. Hort. 6:7.

Halilova, H. and N. Yildiz. 2009. Does climate change have an effect on proline accumulation in pomegranate (Punica granatum L.) fruits? Sci. Res. Essays 4:1543-1546.
Hora, J.J., E.R. Maydew, E.P. Lansky, and C. Dwivedi. 2003. Chemopreventive effects of pomegranate seed oil on skin tumor development in CD1 mice. J. Med. Food 6:157-161.

Huang, T.H., G. Peng, B.P. Kota, G.Q. Li, J. Yamahara, B.D. Roufogalis, and Y. Li. 2005. Pomegranate flower improves cardiac lipid metabolism in a diabetic rat model: Role of lowering circulating lipids. Brit. J. Pharmacol. 145:767-774.

Levin, M. 1994. Comment on the Minnesota transracial adoption study. Intelligence 19:13-20.

Mars, M. 2000. Pomegranate plant material: Genetic resources and breeding, a review. Options Mediterraneennes. Serie A: Seminaires Medit. 42:55-62.

Martin, A.C. 1946. The comparative internal morphology of seeds. Amer. Midl. Nat. 36:513-660.

Olmez, Z., F. Temel, A. Gokturk, and Z. Yahyaoglu. 2007. Effects of sulphuric acid and cold stratification pretreatments on germination of pomegranate (Punica granatum L.) seeds. Asian J. Plant Sci. 6:427-430.

Ozgen, M., C. Drugac, S. Serce, and C. Kaya. 2008. Chemical and antioxidant properties of pomegranate cultivars grown in Mediterranean region of Turkey. Food Chem. 111:703-706

Piotto, B., G. Bartolini, F. Bussotti, A. Asensio, C. García, I. Chessa, C. Ciccarese, L. Ciccarese, R. Crosti, F.J. Cullum, A.D. Noi, P. GarcíaFayos, M. Lambardi, M. Lisci, S. Lucci, S. Melini, J. Carlos, M. Reinoso, S. Murranca, G. Nieddu, E. Pacini, G. Pagni, M. Patumi, F.P. García, C. Piccini, M. Rossetto, G. Tranne, and T. Tylkowski. 2003. Fact sheets on the propagation of Mediterranean trees and shrubs from seed, p. 11-51. In: B. Piotto and A.D. Noi (eds.). Seed propagation of Mediterranean trees and shrubs. APAT I.G.E.R srl., Rome, Italy.

Rawat, J.M.S., Y.K. Tomar, and V. Rawat. 2010. Effect of stratification on seed germination and seedling performance of wild pomegranate. J. Amer. Sci. 6(5):97-99.

Riley, J.M. 1981. Growing rare fruit from seed. California Rare Fruit Growers Year Book 13:1-47.

Sokal, R.R. and F.J. Rohlf. 1995. Biometry: The principles and practice of statistics in biological research, 3rd ed. Freeman, San Francisco, CA.

Stover, E. and E.W. Mercure. 2007. The pomegranate: A new look at the fruit of paradise. HortScience 42:1088-1092.

Wang, C.Y., H.Y. Qu, X.C. Dai, L.L. Shi, Y.J. Liu, and C. Ma. 2010. Pharmacological effects, safety and application of pomegranate (Punica granatum L.). World Sci. Tech/Mod. Traditional Chinese Med. Mater. Med. 12:961-968 (in Chinese with English abstract).

Wang, C.Y., L.L. Shi, L.T. Fan, Y.F. Ding, S. Zhao, Y. Liu, and C. Ma. 2013. Optimization of extraction and enrichment of phenolics from pomegranate (Punica granatum L.) leaves. Ind. Crops Prod. 42:587-594.

Yu, H.M. and J.J. Liu. 2007. Trend analysis of average temperature variations and runoff response in last 40 years in Xinjiang. Water Power. 33(5):13-16 (in Chinese with English abstract).

Yucedag, C. and H.C. Gultekin. 2009. The effect of stratification period and sowing time on germination of pomegranate (Punica granatum L.) seeds. AKÜ Fen Bilimleri Dergisi. 1:87-90. 